OPEN ACCESS

International Journal of Management \& Entrepreneurship Research.

P-ISSN : 2664-3588, E-ISSN : 2664-3596

Vol. 2(1), pp. 11-21, February 2020

Fair East Publishers

Journal Homepage: www.fepbl.com/index.php/ijmer

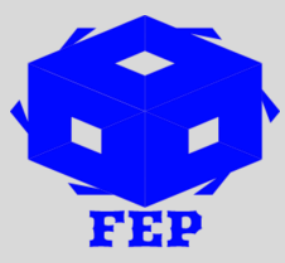

\title{
DETERMINANTS OF CHAMPIONSHIP ATTRACTIVENESS OF POPULAR EVENTS IN BURKINA FASO: THE CRITICAL ROLE OF BIOTOPE, BIOCENOSIS, AND MEDIA ON THE NATIONAL FOOTBALL CHAMPIONSHIP
}

Mamadou Kiékiéta ${ }^{1,4}$, Dr. Théophile Bindeouè Nassè ${ }^{2,3}{ }^{1}$ Amity

University, Uttar Pradesh (India).

${ }^{2}$ University for Development Studies, Wa Campus (Ghana).

${ }^{3}$ Saint Thomas d'Aquin University (Burkina Faso).

${ }^{4}$ University of Ouagadougou (Burkina Faso).

*Corresponding Author: Mamadou Kiekieta

Corresponding Author Email: mamadoukiekieta@yahoo.fr

Article Received: 06-02-20

Accepted: 25-02-20

Published: 05-03-20

Licensing Details: Author retains the right of this article. The article is distributed under the terms of the Creative Commons Attribution-Non Commercial 4.0 License

(http://www.creativecommons.org/licences/by-nc/4.0/) which permits non-commercial use, reproduction and distribution of the work without further permission provided the original work is attributed as specified on the Journal open access page.

\section{ABSTRACT}

The purpose of this paper is to investigate the attractiveness of the popular events in Burkina Faso such as the national championship of football. In the West African context in general, and particularly in Burkina Faso, there are some challenges in the national Championship of football and this study concern is to bring out some solutions to the football issues in the Burkinabe context. There are two (2) approaches in this study. The first approach is a qualitative one. The second approach is a quantitative one. Qualitative data is collected by the mean of a digital recorder through semi-structured interviews and transcribed by hand. Quantitative data is collected by the means of a questionnaire and data is analyzed using Sphinx IQ2. The results show that the Burkinabe national championship attractiveness is strongly related to the biocenosis attractiveness, the biotope attractiveness, the media choice and the media impact.

Keywords: Football, Championship, Attractiveness, Marketing, Sports

\section{INTRODUCTION}

Today, sportive games areas are made for viewers, for fans, and the related services are also implemented to attract and retain the same audience: They are called hospitality venues. As for the sports event, the economic challenge is becoming progressively on top. Sports has moved from simple game to entertainment. In other words, sports culture is increasingly associated 
with monetization. Some football clubs (such as FC Barcelona, Real Madrid, Manchester United, Bayern Munich, Milan FC, etc.) successes showed that sport events attractiveness is ongoing. The wealth of sport event industry normally is linked to economic growth so, organizations or countries which are seeking economic opportunities might consider it. Burkina Faso which is one of the poorest countries in Africa is an example. Profitable activities such as sports events developments might help to boost its economic development. In Burkina Faso, early 1960s, it has already organized within it a national football championship. Although at that time it included only two teams and the game was played on bare land, a team supported by the fans of its region or its area of origin had to play against another team, supported by its fans. Today, competition has spread throughout the territory and now comprises sixteen teams competing in better modern spaces and the young Burkinabe seem to have more and more interest for football. But, since 2000s, technology channels which are more modern are used for providing sports event pictures and information about abroad competitions. Here, football fans are spending most of their free time watching abroad football league competitions. European's football leagues and the stars' jerseys are more and more available in shops and purchased by fans. All these signs proved that there is a great demand for sports' entertainments. However, local championship is less developed. Competitions are taking place in stadiums which are mostly empty. In regard to this situation it is good to ask the subsequent question:

What are some main reasons that can explain the attractiveness of football events in Burkina Faso?

This research aims to identify the determinants of attractiveness in Burkina Faso, and the satisfaction criteria in terms of fans emotional needs. In Africa in general and particularly in Burkina Faso, the meeting of several people in a given place for a celebration has always been a good opportunity to share a communion but also opportunities for economic actors. Burkina Faso remains one of the poorest countries in the world, a predominantly rural population and a weak service sector contribution to the economy while today just by crisscrossing both cities rural areas, we see that this economic opportunity related to the need of distraction exists. Meeting spaces around local drinks confined areas where diffuse series of motion pictures through the dancing bars and gatherings around game areas including football. Everything suggests that the Burkinabe mostly do not like not being in solitude. However, during the competitions "Fasofoot", the report is bitter. Unlike the early years post-independence years that even the media were limited, their predecessors of more importance to this competition, young people today seem to satisfy their need for emotion by marketing the product against the show elsewhere. Yet that activity in the service sector, qualified sports business, not only the national economy needs for its emergence through the creation of SMEs and VSEs, so direct and indirect jobs, but also for the Burkinabe public property psychophysiological be. Just by observing local championship success stories close to home recently in North Africa and the boom of powerful Mazembe of Lubumbashi in the Democratic Republic of Congo, similarities show that the issue of improving the attractiveness of the championship Football in Burkina Faso can be a real research problem. It is for this purpose that we have chosen to focus on this theme. Football is one of the most practiced sports in Burkina Faso. Organized for profit or nonprofit ideal, it has always attracted the attention of people. Reconciliation tournaments, and other sporting event does not go unnoticed in the context. The Burkinabe people love football. Whenever an opportunity arises, fans come in to watch the game either directly or through a TV or radio station. Need emotions, patriotic love or simple fans of stars ... the reasons for the 
attractiveness of the sport may be different but it is certain that the Burkinabe football fans are motivated whenever its representatives earn. Rather, after independence until relatively recently, the spaces where the competitions of the national football championship is disputed overflowed the world. Echoes commentators through the transistors, often in local languages were heard from households. Memberships in clubs officiating for the championship became more and more visible. The major trends were more focused on the EFO (Etoile Filante of Ouagadougou) and ASFA (Association Sportive du Faso): The two most famous rival in the competition. Today, the crowd around the national team is increasingly visible. They welcome African Champions cadet's standards in 2011 that reserved for older women national team vice African champions at the 29th edition of the African Cup of Nations in South Africa in 2013, the mobilization of the people confirmed once more the place of the sporting event in our society. Unfortunately and increasingly, the image of fasofoot does not benefit enough from this opportunity. This popular competition once does not arouse the enthusiasm of yesteryear. Based on a comprehensive analysis of sports events ecosystem of this competition, we want to know the cause of the nonattractiveness of fasofoot.

(i) What is the relationship between championship attractiveness and biocenosis attractiveness?

(ii) What is the relationship between championship attractiveness and biotope attractiveness?

(iii) How and why is championship attractiveness and media choice related?

(iv) Why is championship attractiveness and media impact related?

The main objective is to examine the relationships between the championship attractiveness and the different factor in the national football environment.

The specific objectives of this research are:

(i) to assess the association between championship attractiveness and biocenosis attractiveness.

(ii) to evaluate the association between championship attractiveness and biotope attractiveness.

(iii) to determine the association between championship attractiveness and media choice.

(iv) to examine the association between championship attractiveness and media impact.

\section{LITERATURE REVIEW}

Through all the study, specific concepts are used for explanations. To help all readers to understand more, the following concepts are defined.

\section{- Concepts and definitions of key words}

Football championship: Sports Event where the winner wins the title. A championship is a demonstration sport often that aims to elect eliminating turn or by adding the points in every game, a champion, it can be a team or individual.

Attractiveness: The attractiveness of a territory (city, town, etc.) or regional attractiveness is its ability to attract at one time the implantation of production factors (capital, labor ...), people or tourists. The concept of attractiveness is generally regarded as a positive character, vitality factor for a territory, as the congestion thresholds are not met. In the commercial area, the attractiveness is the ability of a sign to attract buyers. 
Ecosystem: Historically the ecosystem concept was born from the concept of biological communities: people living together (populations are interrelated); then the concept of ecological succession (populations are related to the media). Ecosystem: means house. An ecosystem is a dynamic set of living organisms (plants, animals and microorganisms) that interact with the environment (soil, climate, water, light) in which they live. These definitions highlight two key characteristics of a sporting event, namely both a time and a place in which a sports event occurs. This moment can be defined as a dedicated competition period or a series of matches in the championship. As for the location, it could be a stadium, an arena, a natural area or suited to the sport.

Biotope: The biotope is the living environment where environmental conditions are considered homogeneous and well defined. The habitat of an organism is the medium characterized by parameters (temperature, flora ...) known, in which the body is especially adapted, so it's an environment where some species lives. Each biotope is characterized in principle by the flora and fauna that inhabit it, i.e., by a biocenosis community.

Biocoenosis: All living beings that occupy a given environment (the biotope), interacting with each other and with the environment. Biocenosis along with its habitat, are part of the ecosystem.

Media: Media means all communication channels through which news, entertainment, education, data, or promotional messages are disseminated. Media includes every broadcasting and narrowcasting medium such as newspapers, magazines, TV, radio, billboards, direct mail, telephone, fax, and internet. Media is the plural of medium and can take a plural or singular verb, depending on the sense intended. Media includes: Traditional Media - television, radio, newspapers, magazines, newsletters, tax press and other print publications. Social Media - terms used to describe the new generation of digital, computerized, or networked information and communication technologies. These can take many different forms, including internet forums, blogs, wikis, and podcasts, and picture-, music- and video-sharing. Examples of social media applications are Google Groups, Wikipedia, My Space, Facebook, YouTube, Second Life, Flickr and Twitter.

\section{- Underpinning theory}

This research is focused on the economic theory in order to explain some reasons that draws the fans to see the championship attractive or not attractive.

The economic theory: The economic theory shows that a customer always try to gain an economic advantage in a situation where there is an offer and a demand. Thus the customers tend to see if there is fairness in an offer of a given product. Nasse (2019) emphasises that a customer always try to perceive if the quality of a given product is proportional to its price. Some authors such as Ouédraogo (2007), Livian and Shamba (2014), Nasse et al. (2019) underline that economic criteria are some most important determinants for the customer to make some purchase or consumption decisions.

\section{- Hypotheses}

H1: There is an association between championship attractiveness and biocenosis attractiveness.

Ho: There is not an association between championship attractiveness and biocenosis attractiveness. 
$\mathbf{H}_{2}$ : There is an association between championship attractiveness and biotope attractiveness.

$\mathbf{H}_{0}$ : There is not an association between championship attractiveness and biotope attractiveness.

H3: There is an association between championship attractiveness and media choice.

Ho: $_{0}$ There is not an association between championship attractiveness and media choice.

H4: There is an association between championship attractiveness and media impact.

Ho: There is not an association between championship attractiveness and media impact.

\section{- Research Model}

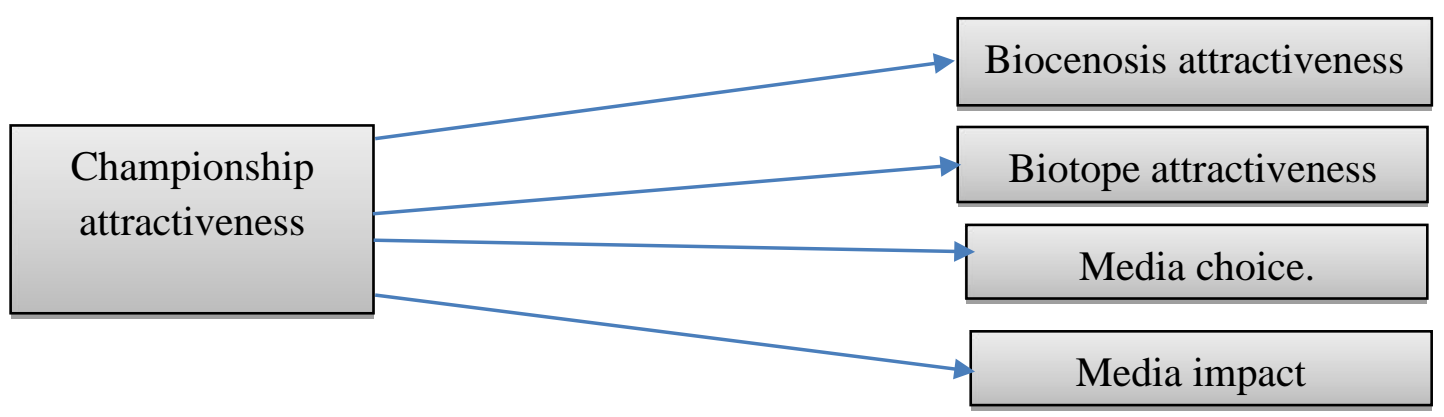

Source: Authors' construct

\section{METHODOLOGY}

Research instruments: The research has been designed with the use of a paper-based questionnaire for the quantitative research and the interview guide for the qualitative research. Research context: The research is conducted in Burkina Faso, especially in the two main cities Ouagadougou and Bobo Dioulasso. The main reason is that these are the cities where some football fans watch more competitions matches. The research is done from the month of June 2016 to the month of July, 2016.

Research sampling procedure: For the qualitative research is focused on a simple random sampling is used and combined with the Delphi method, what allow the selection of 12 experienced experts of the football world and events to be interviewed. The quantitative research is also focused on a simple random sampling technique that allowed some fans to filled the questionnaire. The quantitative sample size is determined by the formula: $n=(p)(1-$

p) / $(\mathrm{e} / \mathrm{Z})^{2} ; \mathrm{p}=$ selected proportion of an attribute $=0.50$ or $50 \%$; e $=$ level of precision $=7.5 \%$, and $\mathrm{Z}=$ degree of confidence $=1.96$ or $95 \%$ confidence (Ganassali, 2009; Hejase and Hejase, $2013) ; \mathrm{n}=0.25 /(0.075 / 1.96)^{2}=170$ people. A sample of 170 people is enough for a 7.5 point error estimate. The total number of respondents is 225 what is sufficient.

Data collection analysis procedure: The quantitative data is collected by the means of a paperbased questionnaire and relevant details including software has been used, with descriptive statistics and test of significance for correlation between variables. Sphinx IQ ${ }^{2}$ software is the one that is used for analysis because of its performance to automatically provides suitable data analysis. The qualitative data is collected with an interview guide and a Dictaphone and then the data is transcribed by hand and then analyzed. 
Ethical considerations: the respondents' identities and the respondents' answers are kept confidential, and they are used just for the purpose of this research. People who do not have any interest in football are not implied. Opinion leaders who have no experience in football events are not concerned.

\section{RESULTS}

For most of the respondents, Burkina Faso's football championship is strongly not attractive. More than $88.4 \%$ agree with this opinion against only $11.6 \%$ disagree. $50 \%$ of the respondents think that the design of the building is a main criterion to make the championship attractive. For them, an attractive area could be safe and secured. For $72.4 \%$ of them, the quality of the game within this biocenosis circle, is not looking good to satisfy their needs. There is also marketing activities around sport event which are not suitable to pull up customers according to $20 \%$ of them. $68.9 \%$ of the respondents use satellites' channels to satisfy their need for sport events. These channels are mainly European channels and Arabic channels. 27\% of them are choosing to go to game location place to watch directly and only $4 \%$ use others channels.

\section{Championship attractiveness and biocenosis attractiveness}

The results on table 1 show that the crossing between "Championship attractiveness" and "biocenosis attractiveness" shows that the relationship is strongly significant because $\mathrm{p}=<0.01$; $\chi^{2}=71.35 ;$ and $\mathrm{df}=3$.

Table 1

Results of the crossing of "Championship attractiveness" and "Biocenosis attractiveness"

\begin{tabular}{lc}
\hline Variable crossing & $\underline{\text { Results }}$ \\
\hline & $\mathrm{p}=<0.01 ; \chi^{2}=71.35 ;$ and $\mathrm{df}=3$ \\
"Championship attractiveness" and "Biocenosis attractiveness" & The relationship is very significant. \\
\hline * $\mathbf{p}=<\mathbf{0 . 0 5}$ & \\
\hline & (Fieldwork, 2016)
\end{tabular}

\section{Championship attractiveness and biotope attractiveness}

The results on table 2 show that the crossing between the variable "Championship attractiveness" and "biotope attractiveness" shows that the relationship is very significant because $\mathrm{p}=<0.01 ; \chi^{2}=52.62$; and $\mathrm{df}=4$.

Table 2

Results of the crossing of "Championship attractiveness" and "Biotope attractiveness"

\begin{tabular}{ll}
\hline \multicolumn{1}{c}{ Variable crossing } & \multicolumn{1}{c}{ Results } \\
\hline Championship attractiveness" and "Biotope attractiveness" & $\begin{array}{l}\mathrm{p}=<0.01 ; \chi^{2}=52.62 ; \text { and } \mathrm{df}=4 \\
\text { The relationship is very significant. }\end{array}$ \\
\hline $\boldsymbol{*} \mathbf{p}=<\mathbf{0 . 0 5}$ & \\
\hline \multicolumn{2}{c}{ (Fieldwork, 2016) }
\end{tabular}

\section{Championship attractiveness and media choice}

The results on table 3 show that the crossing between the variable "Championship attractiveness" and the variable "Media choice" shows that the relationship is strongly significant, because $\mathrm{p}=0.52 ; \chi^{2}=1.32 ;$ and $\mathrm{df}=3$. 
Table 3

\begin{tabular}{ll}
\begin{tabular}{l} 
Results of the crossing of "Championship attractiveness" and "Media choice" \\
\hline Variable crossing
\end{tabular} & \multicolumn{1}{c}{ Results } \\
\hline "Championship attractiveness" and "Media choice" & $\mathrm{p}=0.52 ; \chi^{2}=1.32 ;$ and $\mathrm{df}=3$ \\
& The relationship is not significant.
\end{tabular}

$* \mathbf{p}=<\mathbf{0 . 0 5}$

(Fieldwork, 2016)

\section{Championship attractiveness and media impact}

Finally, the results on table 4 show that the crossing between the variable "Championship attractiveness" and the variable "Media impact" shows that the relationship is strongly significant because $\mathrm{p}=<0.01 ; \chi^{2}=19.60$; and $\mathrm{df}=4$.

Table 4

Results of the crossing of "Championship attractiveness" and "Impact of media"

\begin{tabular}{|c|c|}
\hline Variable Crossing & Results \\
\hline "Championship attractiveness" and "Media impact" & $\begin{array}{l}\mathrm{p}=<0.01 \text { and } \chi^{2}=19.60 ; \mathrm{df}=4 \\
\text { The relationship is very significant. }\end{array}$ \\
\hline$* p=<0.05$ & \\
\hline
\end{tabular}

\section{DISCUSSION OF THE RESULTS}

\section{Championship attractiveness and biocenosis attractiveness}

Some previous research such as Sarstedt et al. (2014) demonstrate that economic factors have effects on sports events, however, the present research points out the strong relationship between championship attractiveness and biocenosis attractiveness. Here, the results show that there is a relationship between Championship attractiveness and biocenosis attractiveness. The null hypothesis $\mathrm{H}_{0}$ is rejected and the $\mathrm{H}_{1}$ is confirmed.

$\mathbf{H}_{1}$ : There is an association between championship attractiveness and biocenosis attractiveness.

\section{Championship attractiveness and biotope attractiveness}

Abosag et al. (2012) also show that brand emotion has some effects on brand extension in the sports world. Nevertheless, the results here rather bring out the link between championship attractiveness and biotope attractiveness. The results show that there is a relationship between Championship attractiveness and biotope attractiveness. The null hypothesis $\mathrm{H}_{0}$ is rejected and the alternative hypothesis $\mathrm{H}_{2}$ is confirmed.

H2: There is an association between championship attractiveness and biotope attractiveness.

\section{Championship attractiveness and media choice}

Some researchers such as Koenigstorfer et al. (2010) find that competitive factors are those that maintain attractiveness in football events. The results of the present research show that there is a relationship between Championship attractiveness and media choice. The null hypothesis $\mathrm{H}_{0}$ is rejected and the alternative hypothesis $\mathrm{H}_{3}$ is confirmed.

H3: There is an association between championship attractiveness and media choice. 


\section{Championship attractiveness and media impact}

The quality of the game and some additional services are known to be some key factors that help to reach fans satisfaction according to Van Leeuwen et al. (2002). The results show that there is a relationship between Championship attractiveness and media impact. The null hypothesis $\mathrm{H}_{0}$ is rejected and the $\mathrm{H}_{4}$ is confirmed.

H4: There is an association between championship attractiveness and media impact.

\section{CONCLUSION AND IMPLICATIONS}

Today, football is one of the most important events in the world and organizations or countries which are seeking economic opportunities might be advised in developing sport events. Burkina Faso is one of the African countries where there are a lot of football fans and where football has been recognized as an important event since the 1990s when it showed its expertise by welcoming and by organizing the football Cup of African Nations event in 1998. Therefore since 1998 some profitable activities such as sports events developments have helped the country to boost its economic development. In Burkina Faso football fans are spending most of their free time watching abroad football league competitions. Nevertheless, less attention is given to the local championship that is less developed and not well managed. Competitions are taking place in stadiums and other free locations which are mostly empty of supporters. There is no doubt that in the African context in general and in the Burkinabe context the national championship of football are facing some tremendous challenges that give some negative impact to its attractiveness. While national championships of football in the western context are very attractive it was interesting too, to investigate the African context and particularly the context of Burkina Faso to find out if the results are the same. The results clearly confirm that the national championship of football in the context of Burkina Faso is not attractive due some factors among which the lack of good quality of the game, the lack of affiliation to a particular football star, the lack of sports promotion. In fact, some previous studies in the context of Burkina Faso showed that consumers are sensitive to the quality of products or services (Nasse, 2019; Nasse, 2016); thus quality and additional services are the key elements to help the Burkinabe championship become more attractive. This research provides some key solutions such as some best marketing approaches and some management tools to help improve not only the attractiveness of the Burkinabe national championship of football but also to fit the expectations of customers (football fans) needs in the context of Burkina. Burkina Faso remains one of the poorest countries in the world, with a predominant rural population (more than $60 \%$ ) and a weak service sector contribution to the economy. Today just by crisscrossing both cities rural areas, we noticed that this economic opportunity related to the need of distraction exists. From meeting spaces around local drinks confined areas where are diffused series of motion pictures through the dancing bars and gatherings around play areas including football. Everything suggests that the Burkinabe mostly do not like not being in solitude. Yet that activity in the service sector, qualified sports business, not only the national economy needs for its development through the creation of SMEs and VSEs, so direct and indirect jobs, but also for the Burkinabe people psychophysiological well-being. Because of these opportunities, government and investors needs to invest more in sport event locations infrastructure. There have to involve international specialists to the project and provide suitable sport marketing training for universities for suitable human resources. The need in term of employment will be 
very wide even in return on investment for SMEs and VSEs, then the whole country. A wide list of implications can be suitable to support sport event attractiveness development in Burkina Faso. But the following are our choice.

In term of infrastructure: Country needs investments in term of modern infrastructures: Stadiums, Arena, and local comfortable and enclosed space. For each region of the country.

More than sixty percent of Burkina Faso's people are living in hinterland, villages and, locations which attract people are mostly nice to see. It is the example of religious sites, dancing bars and restaurants. Even when people don't have nice houses to live, acceptable sites like listed above are more seen everywhere. As we observed frequently, during festivities, break times, people like to have a sit within these sites. This situation let us think that the need of comfortable place exists.

In term of football game quality: The answers of respondents also show that the championship is not attractive:

"The championship no longer attracts the public for lack of quality players. If given more resources to clubs to recruit some foreign players to make the championship level upwards, this would bring more spectators to the stadium". (Respondent 2, sports department head from Burkina Faso, 15 years of experience)

"The quality of football game is not of a high level. African football is being led astray. At the time we have geniuses or natural talents that were doing great things with the ball. The geniuses have disappeared from the Burkinabe Football". (Respondent 7, sports journalist 18 years of experience).

Having teams and players who play well football can be a source of attractiveness for sport event in Burkina Faso. From early of 1960s to now, football was one of the famous sport in the country. Competitions was sometime between village A against village B or region A against region $B$ or district $A$ against district $B$ and each group has been supported by its fans sitting around open place to watch the game. Even today, during festivities and holidays, football competitions between different groups are already practiced and people enjoy it. There is also the attractiveness of enclosed space where, competitions are broadcasted and people pay to watch. This shows that good quality game potential customers exist. So, government and private investors can invest in football academy to have skilled football players for better quality spectacles.

In term of media: The very used channel chosen by customers for sport events are those which are broadcasted by satellite like Canal+, be in sport, so why not use these same channels to advertise and boost local sports events. Local media are also able to help Fasofoot attractiveness, investors can develop it and make it suitable and accessible for consumers. Today, even if internet penetration in Burkina Faso is not very high (9.7\% at 2016) it is very important to notice that information can be more and easy to share without social network channel so sport marketer have to follow up.

In term of diversification of sites activities: During political campaigns for elections, specialist use music singers to attract people in the meeting places. This can also be used for sport event's organizers to boost its attractiveness. There should be a sponsoring policy (Rim, 
2013), the most attractive events help to boost companies' sales and their competitiveness. Some companies that sponsor the national team and it should be continued. For many local companies, help the local championship to go ahead when making sponsoring with them can be a strength.

Future research: Future researches will aim to investigate if the results are the same in other sports area that are different from the domain of football.

\section{References}

Abosag, I., Roper, S., \& Hind, D. (2012). Examining the relationship between brand emotion and brand extension among supporters of professional football clubs. European Journal of Marketing, 46(9), 1233-1251.

Ganassali, S. (2009). Les enquêtes par questionnaires avec sphinx. Paris, PA: Pearson Éducation.

Hejase, A. J., \& Hejase, H. J. (2013). Research methods, a practical approach for business students (Second ed). Philadelphia, PH : Masadir Inc.

Institut National de la Statistique et de la Démographie (2010). Recensement général de la population et de l'habitat 2006, rapport définitif. Ouagadougou, OU: INSD.

Koenigstorfer, J., Groeppel-Klein, A., \& Kunkel, T. (2010). The Attractiveness of national and international football leagues: perspectives of fans of "star clubs" and "underdogs". European Sport Management Quarterly, 10(2), 127-163.

Ladhari, R. (2005). La satisfaction du consommateur : ses déterminants et ses conséquences. Revue de l'Université de Moncton, 36 (2),171-201.

Livian, Y. F., \& Shamba, P. B. (2014). Le management africain introuvable : pour une approche de l'hybridité segmentée. 'Marseille, MA : Communication pour la 4ème Conférence Atlas-AFMI.

Nasse, T. B. (2019). Internal equity and customer relationship management in developing countries: A quantitative and a comparative study of three private companies in Burkina Faso. African Journal of Business Management, 13(1), 37-47. https://doi.org/10.5897/AJBM2018.8663

Nasse, T. B. (2015) Internal equity as a factor of corporate sales growth. Saarbrücken, SA: Lambert Academic Publishing.

Nasse, T. B. (2016). L'équite interne dans la gestion de la relation client: une étude comparative quantitative de trois entreprises privées du Burkina Faso. Journal OuestAfricain des Sciences de Gestion, 1(1), 1-16.

Ouédraogo, A., (2007). Strategic management in African firms: a local perspective. Problems and Perspectives in Management, 5(1), 82-94.

Rim, Z., (2013). Impact du sponsoring sportif de la marque sur la valeur des entreprises tunisiennes. Paris, PA : Education, Université Paris Sud - Paris XI.

Sarstedt, M., Ringle, M. C., Raithel, S., \& Gudergan, S. P. (2014). In pursuit of understanding what drives fan satisfaction. Journal of Leisure Research, 46(4), 419-447.

Van Leeuwen, L., Quick, S., \& Daniel, K. (2002). The Sport spectator satisfaction model: a conceptual framework for understanding the satisfaction of spectators. Sport Management Review, 5(2), 99-128. 


\section{Acknowledgements}

The research team wants to thank the editorial board of Fair East Publishers.

\section{Conflict of Interest Statement}

No conflict of interest has been declared by the authors. 